\title{
Ordenanza municipal y potestad sancionadora: la sorprendente concisión de la STC 132/2001, de 8 de junio
}

\author{
Enrique Orduña Prada \\ Secretario-Interventor de Administración Local
}

Sumario: I. INTRODUCCIÓN. II. LOS HECHOS. III. LA DOCTRINA DE LA SENTENCIA. 1. El doble criterio utilizado para enjuiciar la vulneración del artículo 25.1 CE: la sanción administrativa y las relaciones de sujeción especial. 1.1. La sanción administrativa como categoría jurídica objeto de reserva de ley y sus efectos. 1.2. Las relaciones de sujeción especial como criterio de modulación del principio de legalidad. 2. La colaboración de las Ordenanzas Municipales en la función tipificadora. Criterios de flexibilización y necesidad de norma legal habilitante. 2.1. La naturaleza representativa del Pleno de las Corporaciones Locales como órgano competente para elaborar y aprobar las Ordenanzas. 2.2. La difusa noción de interés local y el contenido de las competencias locales. 3. La inexistencia de ley que otorgue cobertura a la normativa local. IV. CONCLUSIONES.

\section{INTRODUCCIÓN}

El recurso de amparo que resuelve la sentencia objeto de la presente reseña posee un indudable interés que se manifiesta básicamente en dos circunstancias. De una parte, por cuanto versa sobre uno de los aspectos más controvertidos del Derecho municipal español contemporáneo, objeto de atención preferente por la doctrina especializada en los últimos años ${ }^{1}$, como es la legalidad de la regulación de infracciones y sanciones en las materias de competencia y titularidad local a través de Ordenanzas Municipales. Y de otra, porque es la primera ocasión en la que el Tribunal Constitucional (desde ahora, TC) ha procedido a enjuiciar tal materia. Resulta oportuno recordar que este debate no afecta tanto a las normas lo-

\footnotetext{
${ }^{1}$ Las aportaciones doctrinales sobre la materia son de sobra conocidas, pudiendo apreciarse en líneas generales dos posiciones contradictorias. Sin ánimo de exhaustividad, baste recordar que mientras E. GARCÍA DE ENTERRÍA entiende que el ejercicio de la potestad sancionadora por los Entes Locales debe someterse rígidamente al mandato del artículo 25.1 CE y a las exigencias que de él se derivan, vid. «La problemática puesta en aplicación de la LRJ-PAC: el caso del Real Decreto 1398/1993, de 4 de agosto, que aprueba el Reglamento del procedimiento para el ejercicio de la potestad sancionadora. Nulidad radical del reglamento y desintegración general del nuevo sistema legal», REDA, n. ${ }^{\circ} 80,1993$, pp. 665-671, por su parte, A. NIETO considera que, en función de las particularidades y posición constitucional de las Corporaciones Locales, es posible predicar una cierta modulación de la rígida reserva de ley en materia sancionadora, Derecho Administrativo Sancionador, Tecnos, Madrid, 1993, pp. 103 y ss.
} 
cales dictadas al amparo de leyes sectoriales, ya sean estatales o autonómicas, cuanto a aquellas Ordenanzas que, a pesar de desarrollar materias de competencia municipal, regulan infracciones y sanciones que no encuentran una clara cobertura en una ley previa.

Éste sería el caso del supuesto que nos ocupa. El que el recurrente cuestiona que la imposición de una sanción prevista en la Ordenanza Reguladora del Servicio de Vehículos de Alquiler con Aparato Taxímetro del Ayuntamiento de Madrid, de 28 de diciembre de 1979, se adecue al principio de legalidad sancionadora ex artículo 25.1 CE. Una Ordenanza Municipal dictada al amparo del mandato expreso contenido en la Disposición Transitoria Primera del postconstitucional Reglamento Nacional de los Servicios Urbanos e Interurbanos de Transporte en Automóviles Ligeros, de 16 de marzo de 1979.

No debe extrañarnos la considerable atención prestada al tema por la doctrina si tenemos en cuenta que en esta materia concurren una pléyade de institutos, principios y valores jurídicos de distinto orden que dificultan su tratamiento unitario: la limitación de un derecho fundamental de libertad y elemento sustancial del Estado de Derecho, como es la reserva de ley en materia sancionadora; las relaciones entre ordenamientos jurídicos territoriales, el estatal y el local, y el ámbito de normación en el que puede operar este último; la ordenación jurídica de las relaciones entre la Administración y los ciudadanos, que encuentra su correlato pasivo en el ejercicio por aquélla de la potestad sancionadora en los supuestos de incumplimiento por éstos del ordenamiento jurídico; y, por último, sin ánimo de exhaustividad, el papel que ha de desempeñar la garantía constitucional de la autonomía local, una de cuyas manifestaciones más singulares consiste en la facultad de dictar normas en el propio ámbito competencial.

Sobre estos aspectos se han elaborado en los últimos años diferentes propuestas dirigidas a asegurar la legalidad de las normas locales que regulan infracciones y sanciones, existiendo en la actualidad una extensa y variada dogmática sobre el tema ${ }^{2}$. De manera que parece oportuno advertir desde ahora la desigual valoración que nos merecen los diferentes aspectos contenidos en la Sentencia. En esta línea podemos avanzar que la concisa doctrina constitucional, sorprendente en su laconismo, parece construida desde el inicio hacia un fin predeterminado, como es el de otorgar el amparo solicitado por el recurrente. En otras palabras, el TC, a

2 Una síntesis de las diferentes construcciones doctrinales puede verse en J. L. Blasco Díaz, Ordenanza Municipal y Ley, Marcial Pons, Madrid, 2001, pp. 185 y ss. 
nuestro juicio, no ha agotado todas las posibles vías interpretativas ni ha profundizado en exceso en los problemas que el caso suscita y ha preferido optar por reproducir una tradicional doctrina según la cual no existen argumentos de naturaleza jurídica que justifiquen la utilización de algún instituto o categoría jurídica que module la reserva formal de ley cuando se trata de tipificar infracciones y sanciones mediante Ordenanzas Locales ${ }^{3}$. Lo que en último extremo va a suponer que la previa existencia de una ley habilitadora donde se tipifiquen tales infracciones y sanciones se configura como un requisito indispensable para determinar la legalidad de las normas locales con el expresado contenido sustantivo.

En las páginas que siguen a continuación, tras enunciar sucintamente la génesis de la Sentencia, vamos a intentar resumir y examinar su contenido de acuerdo con el iter argumental empleado por la misma. Tarea que, no obstante, se ve limitada por el nivel de generalización de las presentes consideraciones y por la pluralidad de aspectos sobre los que incide aquélla, motivos por los cuales nos detendremos con mayor detalle a la hora de analizar las relaciones entre la Ley y las Ordenanzas Locales.

\section{LOS HECHOS}

Como ya ha quedado apuntado, la STC 132/2001 resuelve un recurso de amparo contra una sentencia del Juzgado de lo Contencioso-Administrativo n. ${ }^{\circ} 6$ de Madrid, que confirmaba un Decreto del Ayuntamiento de Madrid, por el que se imponía al demandante de amparo la sanción de suspensión temporal por tres meses de la licencia de autotaxi de la que era titular. El origen de la sanción era haber sido descubierto en posesión de un talonario de cincuenta recibos no oficiales en el interior de su vehículo mientras prestaba servicio ordinario. Una conducta que, según se desprende del procedimiento sancionador instruido al efecto, y cuyo contenido es asumido por el Decreto del Ayuntamiento, constituye una falta

\footnotetext{
${ }^{3}$ Solución coherente con la jurisprudencia constitucional dictada en materia de las relaciones Ley-Reglamento, ya sean estatales o autonómicos, y potestad sancionadora. No obstante, el Tribunal Supremo (en adelante, TS) no ha mantenido una misma línea argumental sobre la materia, sobre todo en cuanto al papel que le debe corresponder a la legislación básica local como norma habilitante de las infracciones y sanciones reguladas en Ordenanzas Municipales. A título de ejemplo, pueden verse las diferentes soluciones a las que llega el Tribunal, todas ellas referidas a sanciones impuestas a taxistas, de una parte, en las SSTS de 13 de junio de 1995, Ar. 8597 y de 10 de febrero de 1997, Ar. 1407, para las que resulta cobertura legal insuficiente la legislación básica local y, de otra, la STS de 2 de abril de 1991, Ar. 2862, en la que expresamente se establece la posibilidad de que aquélla otorgue cobertura a la sanción impuesta regulada en una Ordenanza Municipal.
} 
grave tipificada en el artículo 51.II.1 de la Ordenanza reguladora del Servicio de Taxis de Madrid ${ }^{4}$.

A los efectos que ahora interesan, el perjudicado funda su pretensión de amparo en la presunta vulneración por la sentencia del órgano a quo de, entre otros derechos fundamentales ${ }^{5}$, el artículo 25.1 CE por «la imposibilidad de que por un Reglamento, y menos aún por la Ordenanza Municipal Reguladora del Servicio de Vehículos de Alquiler con Aparato Taxímetro de 28 de diciembre de 1979, se fije un régimen sancionador distinto del de la Ley que desarrolla».

A diferencia del pronunciamiento de instancia, el TC considera vulnerado el derecho a la legalidad sancionadora del artículo 25.1 CE basando su argumentación en tres criterios. Primeramente, por cuanto califica la suspensión temporal de la licencia de autotaxi como una verdadera sanción administrativa sometida al principio de reserva de ley. En segundo lugar, porque rechaza la posibilidad de aplicar cualquier técnica o instrumento de modulación del reiterado principio de reserva de ley en materia sancionadora. En este sentido, el Alto Tribunal descarta sucesivamente que la categoría de las relaciones de sujeción especial, la naturaleza democrático-representativa del Pleno de las Corporaciones Locales y la existencia de un interés local en relación con la organización del servicio de taxis puedan operar como fundamentos de tal modulación. Por último, al no encontrar una norma de rango legal que habilite expresamente la regulación contenida en la Ordenanza Municipal. Todo lo cual conduce a conceder el amparo solicitado y anular el Decreto del Ayuntamiento y la sentencia de instancia.

Esta decisión origina la redacción de un Voto Particular discrepante formulado por el Magistrado Garrido Falla, al que se adhiere Jiménez de Parga, hoy Presidente del Alto Tribunal, y donde se postula una solución inversa a la del fallo de la mayoría. Para su fundamentación el Magistra-

\footnotetext{
${ }^{4}$ Artículo que establece como falta grave «no respetar los horarios fijados o cualquier otra norma de organización o control establecida».

${ }^{5}$ El actor alega también la violación de los artículos 14 y 24.1 CE, al apreciar que la sentencia recurrida, de una parte, le confiere un trato distinto a como otorgan a otros titulares de licencias sancionados la STS de 13 de noviembre antes mencionada y dos sentencias del Tribunal Superior de Justicia de Madrid de 9 de julio de 1998 y de 13 de julio de 1999, y, de otra, porque el órgano judicial de instancia no siguió el criterio sentado en las sentencias de 1995 y 1998. Ambos motivos son desestimados por el TC, el primero, porque «la invocación del derecho a la igualdad en la aplicación de la Ley (art. $14 \mathrm{CE}$ ) debe ir acompañado de términos de comparación idóneos y no lo son resoluciones dictadas por órganos judiciales distintos», mientras que el segundo lo es por cuanto «la alegada divergencia entre sentencias de distintos órganos judiciales no supone infracción del artículo $24 \mathrm{CE}$ » $\left(\mathrm{FJ} 2 .{ }^{\circ}\right)$.
} 
do disidente acude de una parte, al análisis de la relación que existe entre el taxista y el Ayuntamiento, lo que le lleva a cuestionarse la naturaleza tanto del servicio de taxis como el carácter de verdadera sanción administrativa predicado por la mayoría y, de otra, a la titularidad indudablemente municipal de la competencia sobre el servicio de taxi, que operaría como cobertura legal suficiente de la normativa local ${ }^{6}$.

\section{LA DOCTRINA DE LA SENTENCIA}

\section{El doble criterio utilizado para enjuiciar la vulneración del artículo 25.1 CE: la sanción administrativa y las relaciones de sujeción especial}

\subsection{La sanción administrativa como categoría jurídica objeto de reserva de ley y sus efectos}

El TC inicia el examen de la alegada vulneración del artículo 25.1 CE formulándose dos cuestiones $\left(\mathrm{FJ} 3 .^{\circ}\right)$ : a) si la reacción administrativa ante la conducta del titular de la licencia de auto-taxis es «propiamente una sanción administrativa sometida a reserva de Ley» y, b) si la relación de la Corporación Local con aquél «justifica alguna modulación especial en el disfrute del derecho fundamental a la legalidad sancionadora», es decir, si estamos o no en presencia de una relación de sujeción especial que acredite la modulación del debatido derecho fundamental.

Por lo que respecta a la primera cuestión, el TC no hace si no responder a dos interrogantes: definir el concepto de sanción administrativa, deslindándolo de otras reacciones administrativas más o menos afines; $\mathrm{y}$, en estrecha conexión con lo anterior, delimitar el ámbito de las sanciones respecto de las cuales los ciudadanos ostentan el derecho fundamental a la reserva de ley ex artículo 25.1 CE. En función de estas premisas el TC, reiterando jurisprudencia anterior ${ }^{7}$, afirma con rotundidad que el supues-

\footnotetext{
${ }^{6}$ Interpretación ésta que aparece ya en la STS de 2 de abril de 1991, Ar. 2862, donde se considera plenamente legal una sanción regulada en una Ordenanza Municipal e impuesta a un taxista, al operar como mecanismos de flexibilización de la reserva de Ley ex artículo $25.1 \mathrm{CE}$, tanto la titularidad municipal del servicio, como la relación de sujeción especial que une al sancionado con la Corporación Local. De manera que la concurrencia de tales circunstancias justifica que «el principio de legalidad invocado se [satisfaga] con las invocaciones normativas a preceptos como el contenido en el artículo 21 de la Ley de Bases de Régimen Local 7/1985, de 2 de abril».

${ }^{7}$ STC 61/1990, donde con carácter general definía la sanción administrativa en un sentido amplio como «toda decisión administrativa limitativa de derechos y basada en la apreciación de conductas de personas» $\left(\mathrm{FJ} 6 .^{\circ}\right)$.
} 
to enjuiciado «se trata, con claridad, de una decisión administrativa con finalidad represiva, limitativa de derechos, basada en una previa valoración negativa de la conducta del titular de la licencia a la luz de lo dispuesto en la Ordenanza Municipal del Taxi de Madrid». Concluyendo, en consecuencia, que la suspensión temporal de la licencia es una auténtica sanción administrativa.

Como fácilmente puede inferirse de lo expuesto, dos son los argumentos empleados por el Alto Tribunal para determinar la existencia de una verdadera sanción administrativa entendida en un sentido amplio, como un mal que infringe a los administrados la Administración. De una parte, la incidencia negativa en la esfera de los particulares que lleva aparejada la decisión administrativa y que se traduce en la privación o restricción de derechos de quien la sufre (la suspensión temporal de la licencia por tres meses en el supuesto que nos ocupa). Y, de otra parte, por cuanto «las previsiones sancionadoras del ordenamiento y los actos administrativos que imponen una sanción determinada buscan directa, precisa y deliberadamente causar el daño en que consisten» ${ }^{8}$, que se concreta en el presente caso en la regulación, más o menos extensa, por la Ordenanza Municipal de las sanciones ante eventuales infracciones de su contenido.

De distinto parecer es el Magistrado Garrido Falla, quien en su Voto Particular se cuestiona si la suspensión temporal de la licencia se trata de una verdadera sanción administrativa, supuestamente una expresión del ius puniendi municipal. Ocurre, como es sabido, que la nítida distinción entre «sanciones administrativas» y otros tipos de «medidas restrictivas» de derechos individuales, como son por ejemplo las revocaciones de autorizaciones y licencias, no siempre resulta todo lo clara que sería deseable ${ }^{9}$. De ahí que el Magistrado disidente critique severamente la vis expansiva del artículo 25.1 CE, que ha llevado al TC a ampliar «progresivamente los contornos del concepto de sanción hasta amparar otras medidas restrictivas impuestas por la Administración», lo que en última instancia ha dado lugar a «un amplísimo concepto de sanción administrativa des-

\footnotetext{
${ }^{8}$ Cfr. el reciente trabajo de M. Rebollo Puig, «El contenido de las sanciones», en Justicia Administrativa, número extraordinario de 2001, dedicado monográficamente a Infracciones, sanciones y procedimiento administrativo sancionador, pp. 155-156.

${ }^{9}$ Prueba de ello son los numerosos pronunciamientos jurisprudenciales que tienen por objeto delimitar qué resoluciones administrativas tienen la naturaleza de sanciones; así, por ejemplo, mientras que en materia de taxis la STS de 7 de marzo de 2000, Ar. 7072, entiende que la revocación de la licencia no es una sanción, la STC 61/1990 sí califica la revocación de la licencia de un detective privado como sanción. En este sentido, la STS de 10 de febrero de 1997, partiendo de la STC 181/1990, viene a destacar las dificultades existentes para «trazar una línea divisoria» entre las medidas de revocación sancionadora y las de revocación que sí presentan ese carácter.
} 
conocido en nuestra tradición jurídica y que no diferencia entre realidades jurídicas notoriamente distintas».

No obstante lo que se dirá mas adelante en relación con la naturaleza del servicio de taxis y las relaciones de sujeción especial, y sin entrar en ulteriores consideraciones, valga recordar que en el presente caso, en principio, no estamos en presencia de la revocación o declaración de caducidad de la licencia de autotaxi, medida extrema que puede imponer la Administración, sino ante un supuesto de suspensión temporal de la misma que trae causa de un juicio valorativo en sentido negativo de la conducta del titular de aquélla de acuerdo con lo previamente normado. En otras palabras, la suspensión temporal de la licencia se configura como una restricción temporal de los derechos de su titular, medida menos gravosa para la esfera patrimonial del mismo que la revocación definitiva de aquélla. Es por ello, que entendemos que no le falta razón al Magistrado Garrido Falla cuando crítica severamente la vis expansiva del artículo 25.1 CE, por cuanto en el presente caso parece más apropiado entender que nos encontramos en presencia de una medida tendente a la mejor organización del servicio de taxis y a la protección de los usuarios.

En definitiva, la consecuencia inmediata de que la suspensión temporal de la licencia de autotaxi se trate de una verdadera sanción administrativa consiste en la exigencia de la garantía formal que incorpora el derecho fundamental a la legalidad sancionadora al supuesto que nos ocupa ${ }^{10}$. Esto es, la necesidad de que sea una norma con rango legal el instrumento a través del cual se tipifiquen las conductas ilícitas y se regulen las sanciones correspondientes. Pero tal garantía formal, como es sabido, puede ser objeto de matización a través de la llamada a la colaboración del Reglamento en la función tipificadora. Por ello el TC acude al análisis de la relación que une al recurrente de amparo con la Corporación Local como criterio en el que se puede fundar tal modulación del principio de legalidad, tarea de la que nos ocupamos en el siguiente apartado.

\footnotetext{
${ }^{10}$ Es de sobra conocido que, desde la STC 42/1987, el TC ha interpretado que el contenido del artículo $25.1 \mathrm{CE}$ incorpora una doble garantía: la ya señalada garantía formal, y otra de carácter material y alcance absoluto que se traduce en «la imperiosa exigencia de predeterminación normativa de las conductas ilícitas y de las sanciones correspondientes» (FJ 2. $\left.{ }^{\circ}\right)$. Sobre esta cuestión J. F. MESTRE Delgado, «Los principios de la potestad sancionadora» en J. Leguina Villa y M. Sánchez Morón (dirs.), La nueva Ley de Régimen Jurídico de las Administraciones Públicas y del Procedimiento Administrativo Común, Tecnos, Madrid, 1993, pp. 367-381.
} 


\subsection{Las relaciones de sujeción especial como criterio de modulación del principio de legalidad}

Una vez que el TC ha establecido la exigencia de que ha de ser una norma con forma de Ley la que contenga la regulación de la sanción de suspensión temporal de la licencia, la segunda pregunta que se formula es si de la relación que une al titular de la licencia de autotaxi con la Corporación Local puede deducirse alguna flexibilización del principio de reserva de Ley en materia sancionadora que permita la regulación de infracciones y sanciones a través de normas de rango infralegal. Aunque un exhaustivo análisis de la materia excedería con mucho las pretensiones de estas líneas, para seguir una ordenada exposición de la argumentación empleada por el TC, conviene dejar constancia de la hermenéutica constitucional en esta materia por cuanto es la primera ocasión en la que el TC ha tenido oportunidad de enjuiciar si los taxistas están sometidos a una relación especial de sujeción ${ }^{11}$.

El TC inicia su argumentación afirmando con carácter general que, «la categoría "relación especial de sujeción" no es una norma constitucional, sino la descripción de ciertas situaciones y relaciones administrativas donde la Constitución, o la Ley de acuerdo con la Constitución, han modulado los derechos constitucionales de los ciudadanos». Añadiendo a renglón seguido que, «incluso en el ámbito de una "relación de sujeción especial" una sanción carente de toda base normativa legal resultaría lesiva del derecho fundamental que reconoce el artículo $25 \mathrm{CE}$ » (FJ 4. $\left.{ }^{\circ}\right)$. Con ello, el TC no viene sino a reiterar una consolidada jurisprudencia ${ }^{12}$, al interpretar el principio del artículo 25.1 CE en el sentido de que sólo la Constitución o la Ley pueden establecer los criterios necesarios para modular los derechos de los particulares cuando éstos se relacionan con la Administración.

En aplicación de dicha doctrina al supuesto objeto del litigio, el TC niega que la relación controvertida se trate de una situación de sujeción especial en función de dos criterios: a) porque en materia de servicio de taxis «ningún precepto constitucional prevé ni explícita ni implícitamente la limitación de derechos constitucionales en un ámbito de actividad

\footnotetext{
11 Cuando el TS ha tenido ocasión de pronunciarse sobre la naturaleza jurídica de la debatida relación se ha limitado, sin mayores precisiones, a señalar que se trata de una relación de sujeción especial por tratarse de un servicio público impropio; $v$. gr. SSTS de 2 de abril de 1991, Ar. 2862, de 13 de noviembre de 1995, Ar. 8597, y de 10 de febrero de 1997, Ar. 1407.

12 Entre otras, pueden verse la STC 219/1989, FJ 2. ${ }^{\circ}$ y las SSTS de 1995 y 1997, citadas supra, en relación con sanciones impuestas en el ámbito del servicio de taxis.
} 
económica privada, aunque esté intervenida y reglamentada»; $\mathrm{y}, \mathrm{b})$ porque «tampoco ninguna Ley vigente al tiempo de la infracción sancionada modulaba el disfrute de los derechos fundamentales de quien hoy pide nuestro amparo». Concluyendo, y aquí radica la importancia del fallo constitucional en la materia que nos ocupa, que «[...] con independencia de cómo se denomine la relación que une al titular de la licencia de autotaxi con su Ayuntamiento, no hay fundamento alguno para que la sanción impuesta al recurrente carezca de cobertura legal que, con carácter general, exige el artículo 25.1 CE» (FJ 4. $\left.{ }^{\circ}\right)^{13}$.

La exigencia de Ley habilitadora previa como parámetro de la legalidad de las sanciones impuestas en aplicación de la regulación contenida en las Ordenanzas Municipales se recoge ya en las reiteradas SSTS de 13 de junio de 1995 y de 10 de febrero de 1997 antes citadas. La novedad en el presente caso radica en que nunca antes, ni el TC ni el TS habían excluido al servicio de taxis del ámbito de las relaciones de sujeción especial. Con ello, el TC realiza una doble función: de una parte, fija el criterio que utilizará más adelante en la búsqueda de una norma que otorgue cobertura legal suficiente a la Ordenanza Municipal, y, de otra, cierra el paso a pretendidas interpretaciones más o menos extensivas de la categoría de las relaciones de sujeción especial ${ }^{14}$, conectando al tiempo con la doctrina mayoritaria que reduce los supuestos de aquélla a los previstos en la Norma Fundamental y explícitamente en el artículo 127.3 de la LRJPAC ${ }^{15}$.

Esta interpretación del TC en orden a la calificación de la naturaleza de la relación entre la Corporación Local y el titular de la licencia, y las consecuencias que de ella se derivan, va a ser una de las cuestiones sobre las que articula su Voto Particular el Magistrado disidente. En efecto, Garrido Falla, tras lamentar la oportunidad perdida por el TC para delimitar el

\footnotetext{
${ }^{13}$ La cursiva es nuestra.

${ }^{14}$ Sin ánimo de exhaustividad y obviando los supuestos más conocidos - militares y miembros de las fuerzas de seguridad, funcionarios e internos en establecimientos penitenciarios - el TS ha entendido que se encuentran en tal categoría situaciones tan heteróclitas como la organización de mercados municipales, STS de 29 de mayo de 1990, Ar. 5621; los promotores de viviendas, STS de 8 de junio de 1988, Ar. 5070; o, por último, los internos en una residencia de ancianos, STS de 27 de septiembre de 2000, Ar. 8445. Resulta de utilidad E. SÁnChez Goyanes, La potestad normativa del municipio español, El Consultor, Madrid, 2000, donde se expone cómo los Ayuntamientos, para salvar la legalidad de las sanciones contenidas en sus propias Ordenanzas, defienden en los correspondientes procesos que los ciudadanos se encuentran respecto de aquellas Administraciones en una relación de sujeción especial por la utilización del dominio público, invirtiendo con ello un principio tradicional del Derecho público contemporáneo.

15 En este sentido, y en referencia al ámbito local, I. SAnz Rubiales, «Principio de legalidad y potestad sancionadora en la Administración Local», REALA, n. ${ }^{\circ}$ 264, 1994, p. 688.
} 
marco de aplicación de la doctrina de las relaciones especiales de sujeción en el concreto ámbito del servicio de taxis, entiende, al igual que el Letrado del Ayuntamiento de Madrid en su escrito de alegaciones, que la relación controvertida consiste en una relación de sujeción especial.

Para ello excluye el servicio público de taxis de la libertad de empresa amparada por el artículo $38 \mathrm{CE}$, configurándolo, por el contrario, como una actividad de interés público en la que la intervención administrativa, a través de la Ordenanza Local, se justifica por estar en juego «desde la existencia misma del servicio, hasta la protección de los abusos de que puede ser objeto el usuario». De tal manera que, «la actividad del taxista deja de ser una actividad producto de la libertad de empresa para convertirse en una actividad sujeta a una estricta reglamentación en la que, junto a un cuadro de deberes y obligaciones, se tipifican las infracciones que derivan de su incumplimiento y las sanciones que tal incumplimiento acarrea» $\left(\mathrm{FJ} 3 .^{\circ}\right)$.

De todo lo cual deduce que «la vigencia de las Ordenanzas tienen su apoyo en el hecho de que, al encontrarnos ante una relación especial de sujeción, el principio de rigurosa legalidad quedaba relativamente flexibilizado». La consecuencia que se deriva de tal perspectiva no es ni más ni menos que la normativa local sería bastante para ofrecer la cobertura legal suficiente a la sanción impuesta ${ }^{16}$.

La lectura de los párrafos transcritos pone de relieve cómo ambos pronunciamientos atribuyen una naturaleza diferente al servicio de taxis, lo que les lleva a conclusiones dispares. A los efectos que ahora interesan, y sin entrar en ulteriores especulaciones, debemos llamar la atención sobre la idea de que dicho servicio ha sido considerado tradicionalmente como un servicio público impropio ${ }^{17}$, por cuanto falta en él un elemento esencial de todo servicio público como es la publicatio. Configurándose, no obstante, como una actividad «casi pública», ya que es objeto de una intensa reglamentación e intervención por parte de los poderes públicos y porque la titularidad corresponde a los municipios, quedando su ejercicio reservado a la obtención de autorización administrativa a través de la correspondiente licencia ${ }^{18}$. Mientras que la organización de tal servicio se

\footnotetext{
${ }^{16}$ Como se puede observar, Garrido Falla sigue los mismos criterios que ya empleara la STS de 2 de abril de 1991 citados anteriormente.

17 SSTS de 10 de febrero de 1997, Ar. 1407 y de 16 de noviembre de 1998, Ar. 8225, entre otras.

${ }^{18}$ Sobre la naturaleza del servicio de taxis vid. el trabajo de J. M. ${ }^{a}$ Socías CAMACHO, «La prestación del servicio de taxis y libertad de empresa», REALA, n. ${ }^{\circ} 284,2000$, pp. 733-766.
} 
configuraría como una actividad privada, enmarcada en el ámbito de la libertad de empresa, no integrándose el taxista-empresario en la organización administrativa.

En este sentido, debemos hacer notar que tal interpretación nos llevaría a entender que las medidas restrictivas de derechos impuestas a los titulares de licencias de autotaxi no lo son en virtud de un presunto ius puniendi municipal, esto es, no son propiamente sanciones, sino que son expresión de una función correctora ${ }^{19}$ de la organización del servicio en orden a preservar la óptima prestación del mismo a los usuarios. Además, la exclusión del taxista-empresario del seno de la organización administrativa supondría, en última instancia, que no quedaría sujeto a una relación de sujeción especial con la misma, sino que, al contrario, vendría «a suplantar a la organización administrativa con su propia empresa» ${ }^{20}$.

Retomando el hilo argumental de la Sentencia, podemos concluir que el TC ha avanzado un paso más en limitar en sus justos términos una discutible categoría jurídica, empleada tradicionalmente como criterio de modulación del derecho fundamental a la legalidad sancionadora, y que ha originado normalmente mayores problemas de los que ha pretendido resolver. Mas, aunque intrínsecamente nada se puede reprochar a tal decisión, surgen algunas dudas en orden a la oportunidad y fundamentación de la misma en el presente caso. Quizá hubiese sido deseable una mayor concreción en la doctrina del TC, puesto que, en principio, parece excluir el servicio de taxis del ámbito de las relaciones de sujeción especial en el concreto caso que enjuicia al no encontrar una norma legal que dé cobertura a la sanción impuesta por la Corporación Local.

19 Empleamos la expresión «función» entendida como «la consideración de la potestad desde el punto de vista de las atribuciones de un órgano administrativo», cfr. F. GARrido Falla, Tratado de Derecho Administrativo, 12. ${ }^{a}$ edic., Tecnos, Madrid, 1994, p. 393.

${ }^{20}$ Cfr. J. M. Socías Camacho, op. cit., p. 764. 


\section{La colaboración de las Ordenanzas Municipales en la función tipificadora. Criterios de flexibilización y necesidad de norma legal habilitante}

\subsection{La naturaleza representativa del Pleno de las Corporaciones Locales como órgano competente para elaborar y aprobar las Ordenanzas}

Descartado por el TC que el servicio de taxis pueda calificarse como una relación de sujeción especial que justifique la modulación del principio de reserva de ley sancionadora, procede a continuación a analizar las relaciones entre ordenamientos territoriales $\left(\mathrm{FJ} \mathrm{5.} .^{\circ}\right)$ y la posibilidad de aplicar otros instrumentos de flexibilización de la rígida reserva de ley formal distintos de aquél. Con tal fin acude, con carácter preliminar, a reseñar sucintamente la teoría general de la doctrina constitucional sobre las relaciones entre Ley y Reglamento, ya sean estatales o autonómicos. Esto es, sobre las normas emanadas por dos órganos, Parlamento y Ejecutivo, procedentes de un mismo Ente territorial.

Para ello reitera anteriores fallos jurisprudenciales de los que podemos retener básicamente dos ideas. La primera, que el artículo 25.1 CE «obliga al legislador a regular por sí mismo los tipos de infracción administrativa y las sanciones que le son de aplicación, sin que sea posible que, a partir de la Constitución, se puedan tipificar nuevas infracciones ni introducir nuevas sanciones o alterar el cuadro de las existentes por una norma reglamentaria cuyo contenido no esté suficientemente predeterminado o delimitado por otra con rango de ley» (SSTC 305/1993, FJ 3..$^{\circ}$ y 6/1994, $\mathrm{FJ} 2 .^{\circ}$ ). Y, la segunda idea, que la función que corresponde al Reglamento es el desarrollo y precisión de los tipos de infracciones previamente establecidos por la Ley.

En definitiva, lo anterior viene a significar que las normas postconstitucionales que tipifiquen infracciones y sanciones obligatoriamente deben, pues así lo demanda el artículo 25.1 CE, tener la forma de leyes, quedando para tal función vedada la intervención de normas infralegales, aunque no así su ulterior colaboración con aquéllas. De esta manera quedan excluidos de la función tipificadora los Reglamentos independientes no meramente ejecutivos de las Leyes.

Si bien esta impecable construcción resulta perfectamente aplicable a las relaciones entre Ley y Reglamento, ya sea en el ámbito estatal o en el autonómico, el TC reconoce que cuando se trata de examinar las relaciones entre Ley y Ordenanzas Municipales existen principios constitucio- 
nales que operarían como factores o elementos de flexibilización de la formalista exigencia de la reserva de ley. Razón por la cual toma en consideración la doctrina de la STC 233/1999, en la que se consagra una concepción flexible de aquella reserva en materia de tributos locales, al partir de un doble parámetro normativo. Por un lado, la naturaleza democrático-representativa del Pleno de las Colectividades Locales como órgano competente para elaborar y aprobar las normas locales ${ }^{21} \mathrm{y}$, de otro, la siempre difusa noción de interés local, que el TC ampara en la expresa consagración en nuestra Norma Fundamental de la garantía constitucional de la autonomía local, y que en último extremo implica la imposibilidad de que la Ley contenga una regulación agotadora de las materias que desarrolla, debiendo dejar un espacio para la normación local.

El TC, no obstante, sin entrar a valorar la naturaleza democrático-representativa de las Asambleas Locales, excluye del supuesto enjuiciado el criterio de flexibilidad de la reserva de ley que se acaba de exponer «por la diferencia intrínseca entre la reserva de ley tributaria y la sancionadora»y, por cuanto la doctrina de referencia se forma en relación con las tasas y precios públicos «donde se identifica un elemento sinalagmático muy relevante para la concepción flexible de la reserva de ley» (FJ 5. ${ }^{\circ}$ ).

Al nivel de generalización de las presentes consideraciones, resulta oportuno apuntar algunas observaciones que se deducen de la exclusión por el TC de tales criterios de flexibilización de la reserva de Ley. Por otra parte, nada más alejado de nuestro ánimo el proponer soluciones alternativas, limitándonos a poner de relieve cómo, a nuestro juicio, el Alto Tribunal con su concisa doctrina en esta materia no ha extraído todas las posibles consecuencias que le brinda nuestra Norma Fundamental ni ha disipado nuestras dudas, evidentemente. Para ello es oportuno centrar la atención en las relaciones entre Ley y Ordenanza Local y los criterios que operarían como presupuestos de flexibilización de la reserva de ley, como son la naturaleza representativa del Pleno de los Entes Locales y la categoría del interés local. Sin olvidar, en cualquier caso, el papel que ha de desempeñar la garantía constitucional de la autonomía local en la materia que nos ocupa.

${ }^{21}$ No obstante, debemos tener en cuenta que la operatividad práctica de este criterio no es compartida unánimemente por la doctrina. Así, T. R. FERNÁNDEZ RoDRíguEZ afirma que la «autenticidad democrática» del gobierno local en nada influye en el régimen jurídico propio de la potestad reglamentaria local, vid. «La potestad reglamentaria de las Corporaciones Locales», en Cuadernos de Derecho Judicial. Administración Local, XXIX, CGPJ, Madrid, 1995, p. 209. Por el contrario, y en relación a la STC 233/1999, pone el acento en tal carácter democrático S. ANíBArro Pérez, en «Las competencias normativas de las Corporaciones Locales sobre sus tributos propios», Revista de Estudios Locales (CUNAL), n. ${ }^{\circ} 42,2000$, pp. 58 y ss. 
En este sentido, podemos partir de la constatación de una realidad de naturaleza constitucional, tal y como observó en su momento J. GARCÍA MORILLO ${ }^{22}$, que se concreta en el hecho de que la extensión del principio de reserva de ley se configura como un obstáculo constitucional para lograr un alto grado de autonomía local. Es decir, tal principio no sólo «impide a los entes locales la adopción de políticas propias en no pocas materias», sino que además obliga «a que la regulación sea, como la emanada de toda norma de rango de ley, universal y general, lo que forzosamente impide actuar de acuerdo con las circunstancias específicas de cada lugar». Problema que se agrava cuando la reserva de ley de que se trata versa, como sucede en el presente caso, sobre materia sancionadora.

Lo anterior, más allá de la mera especulación dogmática, es fácilmente constatable si descendemos del plano teórico a la realidad. Para ello basta acudir al ordenamiento jurídico positivo y centrarnos en la posición que ocupan las Colectividades Locales en el esquema organizativo territorial del Estado. Como se ha repetido insistentemente desde 1978, éstas aparecen como el primer escalón en las relaciones entre la Administración y los ciudadanos, tanto en su vertiente positiva - prestación de servicios-, como negativa - imposición de deberes y obligaciones-. Y es precisamente en este último aspecto donde, en no pocas ocasiones, el incumplimiento de las citadas obligaciones impuestas por los Entes Locales quedan impunes por falta de tipificación legal previa ${ }^{23}$.

Partiendo de tal presupuesto, y por lo que respecta al carácter democrático-representativo del Pleno, resulta oportuno precisar que el mismo aparece íntimamente ligado a la configuración de la autonomía local no exclusivamente como de naturaleza burocrático-administrativa, sino también como principio en el que concurre una decidida vocación política, de ahí que el artículo 140 CE distinga entre gobierno y administración municipal.

Desde esta perspectiva es posible, en relación con el Pleno Local, establecer un vínculo entre el mandato representativo contenido en los artícu-

${ }^{22}$ Cfr. J. García Morillo, La configuración constitucional de la autonomía local, Marcial Pons, Madrid, 1998, p. 32. En el mismo sentido, L. Parejo Alfonso apuntó ya la procedencia de actualizar el concepto de reserva de ley en cuanto a las relaciones entre ésta y las Ordenanzas Locales, en Administrar y juzgar: dos funciones constitucionales distintas y complementarias, Tecnos, Madrid, 1993, p. 95, incidiendo de nuevo en ello in extenso en, La potestad normativa local, Marcial Pons, Madrid, 1998, pp. 65 y ss.

${ }^{23}$ Vid. J. L. Blasco Díaz, op. cit., p. 184, quien señala como causa de tal vacío legal el desconocimiento por el legislador de la conflictividad de las relaciones vecinales, perfectamente conocido, como es natural, por las propias instancias locales. 
los 23.2, 140 y 141.2 CE y la existencia de una «acción de gobierno o función de dirección política local» ${ }^{24}$. De manera que los miembros corporativos elegidos mediante sufragio universal se configuran como auténticos representantes populares, manifestación de la voluntad política de los vecinos, y con legitimidad para elegir, bajo su propia responsabilidad, entre las diferentes opciones posibles las que mejor respondan a los intereses de aquéllos. Lo que se traduciría en la necesaria determinación de fines, prioridades, y valoración de resultados, criterios todos ellos de oportunidad política que se manifiestan con el expresivo nombre de «gobierno de las diferencias» ${ }^{25}$. Y todo ello por cuanto el sistema local no es homogéneo y uniforme en su conjunto, respondiendo a demandas diferentes que implican que las necesidades de los Municipios no son iguales en todo tiempo y lugar, dependiendo de factores extrajurídicos como la ubicación geográfica, la población, la capacidad financiera, el desarrollo industrial y urbano, etc.

En función de todo ello se puede inferir que la naturaleza democrático-representativa del Pleno de las Corporaciones Locales, en cuanto órgano competente para elaborar y aprobar las Ordenanzas Municipales, ha venido a incidir en el régimen jurídico de la potestad normativa local. En este sentido, baste recordar que tal característica ya ha sido utilizada por el propio Alto Tribunal como argumento para flexibilizar la estricta y formalista reserva de ley, ampliando con ello el ámbito de normación de las Ordenanzas Locales. Así, en el caso señalado de los tributos locales en relación con la potestad normativa local, la STC 233/1999 ha venido a reconocer que la imposición y ordenación de los tributos efectuada por el Pleno, en tanto y cuanto se trata de un órgano cuyos miembros son elegidos por sufragio universal en los términos de la $\mathrm{CE}$, la legislación electoral y la LrBRL, «respeta escrupulosamente las exigencias de autoimposición o autodisposición de la comunidad sobre sí misma que, como hemos venido señalando, se adivinan en el sustrato último de la reserva de ley». Añadiendo que, «en virtud de la autonomía de los Entes Locales constitucionalmente garantizada y del carácter representativo del Pleno de la Corporación municipal, es preciso que la Ley estatal atribuya a los Acuerdos dictados por éste [...] un cierto ámbito de decisión acerca de los tributos propios del Municipio [...]. Es evidente, sin embargo, que este ámbito de libre decisión a los Entes Locales — desde luego mayor que el que pudiera relegarse a la normativa reglamentaria estatal—, no está

\footnotetext{
${ }^{24}$ En este sentido, J. García RocA, «El concepto actual de autonomía local según el bloque de la constitucionalidad», REALA, n. ${ }^{\circ} 282,2000$, p. 50.

${ }^{25}$ Así califica al Gobierno Local J. GarCía Morillo, op. cit. p. 44.
} 
exento de límites», como pueden ser la preservación de la unidad del ordenamiento y la igualdad de la posición de los contribuyentes (FJ $\left.10 .^{\circ}\right)$.

A cuanto acabamos de exponer debemos añadir que el señalado carácter representativo del Pleno de las Corporaciones Locales, ha sido un argumento empleado por Alejandro NIETO ${ }^{26}$ con el objeto de resolver la espinosa cuestión de que la estricta aplicación del principio de legalidad supone, en un número singular de ocasiones, que las Colectividades Locales se encontrarían abocadas a la inconstitucionalidad cuando ejercitan su potestad sancionadora por la ausencia de habilitación legal expresa de la tipificación de la oportuna infracción. De manera que la Ordenanza Local, elaborada de acuerdo con los principios de discusión y publicidad y aprobada por el Pleno de la Corporación, vendría a cumplir el requisito de la Ley formal. Justificándose tal aseveración en que las relaciones Ley y Reglamento, estatales y autonómicos, no pueden asimilarse en bloque a las relaciones entre la Ley y las Ordenanzas Locales. En definitiva, de lo que se trata es de que la norma local no sería un mero Reglamento ejecutivo de la Ley estatal o autonómica, sino que, de acuerdo con tal criterio democrático, tendría reservado un ámbito de actuación más amplio que aquél.

\subsection{La difusa noción de interés local y el contenido de las competencias locales}

Excluido del razonamiento inductivo el criterio de la naturaleza representativa de la Asamblea Local, el TC procede a valorar la siempre difusa categoría del interés local y su incidencia en la reserva de ley sancionadora. Para ello sienta el criterio de que tal reserva, cuando se trata de regular infracciones y sanciones, debe ser flexible siempre y cuando, por intervenir el interés local, exista un amplio campo para la regulación municipal y ésta sea aprobada por el Pleno. Pero tal flexibilidad «no sirve [...] para excluir de forma tajante la exigencia de ley. Y ello porque la mera atribución por ley de competencias a los Municipios - conforme a las exigencias del art. 25.2 LBRL - no contiene en sí la autorización para que cada Municipio tipifique por completo y según su propio criterio las infracciones y sanciones administrativas en aquellas materias atribuidas a su competencia».

\footnotetext{
26 A. Nieto, Derecho Administrativo Sancionador, Tecnos, Madrid, 1993, p. 107. Incide en el carácter democrático del Pleno F. GonzÁlez NAVARro, llegando a afirmar que las Ordenanzas locales poseen una sustancia democrática de la que carecen los reales decretos reglamentarios o las órdenes ministeriales, en J. González Pérez y F. González Navarro, Comentarios a la Ley de Régimen Jurídico de las Administraciones Públicas y Procedimiento Administrativo Común (Ley 30/1992, de 26 de noviembre), II, 2. ${ }^{a}$ edic., 1999, p. 2504.
} 
Concluyendo su razonamiento con la afirmación de que «no hay correspondencia, por tanto, entre la facultad de regulación de un ámbito material de interés local y el poder para establecer cuándo y cómo el incumplimiento de una obligación impuesta por Ordenanza Municipal puede o debe ser castigada. La flexibilidad alcanza al punto de no ser exigible una definición de cada tipo de ilícito y sanción en la ley, pero no permite la inhibición del legislador» (FJ 6. ${ }^{\circ}$ ).

Conviene tener presente que en la actualidad, tal y como se ha recordado reiteradamente, son muy escasas las materias que pueden atribuirse exclusivamente al interés local pero, a la inversa, son también escasas aquellas materias en las que no entra en juego este interés. Por lo que respecta al servicio de taxis, de la lectura conjunta de los artículos 25.2.11) y 86.3 LrBRL podemos deducir que estamos en presencia de un supuesto en el que coinciden una de las competencias de las enumeradas en el primer artículo señalado y, asimismo, una de las materias objeto de reserva a favor de los Entes Locales de las previstas en el segundo precepto, pero sin que estemos en presencia de servicios mínimos y obligatorios. En conclusión, es factible afirmar que dichas actividades y servicios reservados son verdaderas competencias locales, y por lo tanto, el precitado servicio de taxis es una de tales competencias en la que claramente concurre el interés local ${ }^{27}$.

Determinada de forma sucinta la competencia municipal sobre el servicio de taxis $y$, en consecuencia, la existencia de un interés local sobre la materia, valga recordar que la Sentencia comentada viene a negar la eficacia práctica de tal interés con el objeto de demandar la necesaria existencia de una ley en la que previamente se determinen las infracciones y sanciones que posteriormente deben recogerse en las correspondientes Ordenanzas Municipales. Con ello, el TC rechaza la posibilidad de que la atribución de una competencia por el legislador básico local permita a las Corporaciones Locales «[tipificar] por completo y según su propio criterio las infracciones y sanciones administrativas en aquellas materias atribuidas a su competencia».

De esta hermenéutica constitucional se desprende con claridad que el Alto Tribunal ha acudido a la clásica interpretación de la vinculación de los Entes Locales con la Constitución y las Leyes en el sentido de entenderla como una vinculación positiva. Es decir, las relaciones entre las

\footnotetext{
27 Tomamos la clasificación de los distintos supuestos de reserva de servicios a favor de los entes locales y su entrecruzamiento con las competencias locales de J. M. Díaz Lema, Los Monopolios Locales, Montecorvo, Madrid, 1994, pp. 51 y ss.
} 
normas infralegales locales y las Leyes estatales y autonómicas se regirían por los mismos parámetros que los existentes entre Ley y Reglamento. Pero el análisis de tal clase de relación no se agota, como es sabido, en esa clase de vinculación, por lo que algunos autores, e incluso el Consejo de Estado ${ }^{28}$, han venido a proclamar que en tales supuestos nos encontraríamos ante un ejemplo de vinculación negativa ${ }^{29}$. En otros términos, lo que se postula es que las Corporaciones Locales, a través de las Ordenanzas Municipales, podrían llegar a incidir en todos aquellos aspectos que no estuvieran expresamente prohibidos por la Ley. En definitiva, lo que se persigue es ampliar el campo normativo de las Entidades Locales, partiendo del presupuesto de que las Ordenanzas Locales no son meros Reglamentos ejecutivos de las Leyes sectoriales, ya sean estatales o autonómicas, ni, por lo tanto, responden a la tradicional dialéctica entre Ley y Reglamento ${ }^{30}$.

\section{La inexistencia de ley que otorgue cobertura a la normativa local}

El punto final de la argumentación constitucional se centra en la búsqueda de un elemento que se puede deducir fácilmente de la lectura de los párrafos transcritos: la necesaria exigencia de que una norma con rango de ley ofrezca cobertura suficiente a la tipificación de infracciones y sanciones contenida en la Ordenanza Municipal. Tal requisito es reiteradamente invocado al analizar la naturaleza de la resolución administrativa, la relación que liga al titular de la licencia con la Corporación Local, y, en último término, al examinar la incidencia del interés local y el carácter democrático del Pleno. En este sentido, hay que hacer notar que las conclusiones a las que llega el Alto Tribunal cuando enjuicia los precitados principios, partiendo del dato de que el Reglamento Nacional de Trans-

${ }^{28}$ En el Dictamen del Consejo de Estado n. ${ }^{\circ} 1749 / 1994$, Sección $3 .^{\text {a }}$, de 23 de febrero de 1995 , en
relación con las Ordenanzas Locales y la potestad sancionadora se define la vinculación negativa de
las Entidades Locales a la Constitución y a la Ley, en el sentido de que aquéllas «gozan en el ámbito
de su competencia y en el marco definido de la Ley de Régimen Local, de una potestad de Ordenan-
za y de una potestad sancionadora, de modo que podrán promulgar Ordenanzas que no estén en
oposición con la Ley, siempre que no excedan del ámbito previsto en la ley de cobertura». Son de
interés los reparos que formula al Dictamen del Consejo de Estado, T. R. FerNÁnDEZ RoDRíGuEZ,
op. cit., en función de los tres argumentos sobre los que aquél realiza su exposición: el histórico, el
práctico y el carácter democrático del Pleno de las Entidades Locales.

29 Vid., entre otros, C. PAREJA I LozANo, «Autonomía y potestad normativa de las Corporaciones Locales», RAP, n. ${ }^{\circ} 138,1995$, pp. 107-142.

${ }^{30}$ En este sentido pueden verse, por ejemplo, C. Pareja i Lozano, op. cit.; L. M. ${ }^{a}$ Díez-Picazo, «Forza di legge e principio di autonomia», en G. Rolla y Eleanora Ceccherini, Profili de Diritto Parlamentare in Italia e in Spagna, G. Giappichelli Editore, Torino, 1997, p. 218. 
portes en virtud del cual se desarrolla la Ordenanza Municipal es posterior a la Constitución, inducen a atisbar el infructuoso resultado de la citada búsqueda.

El TC dedica los FF.JJ. 7..$^{\circ}$ y.$^{\circ}$ a buscar el fundamento legal de las infracciones y sanciones contenidas en la Ordenanza Municipal examinando dos bloques normativos: la legislación básica local y la legislación sectorial, tanto estatal como autonómica. Por lo que respecta al primero de los bloques señalados, y en relación a las infracciones, entiende que ni del artículo 4.1.f), ni del 25.2.11 LrBRL se puede extraer algún criterio material que «encauce la tipificación de ilícitos administrativos en relación con los servicios de transporte de autotaxi». Mientras que en materia de sanciones tampoco operaría el artículo 59 del TRRL, por cuanto «sólo prevé las multas máximas "por infracción de Ordenanzas"», ni contiene una explícita graduación de las sanciones en función de la antijuridicidad de los ilícitos, regulando las mismas según tramos de población.

En esta misma línea discursiva, el TC reitera la interpretación que el TS ha empleado en algunos fallos jurisprudenciales anteriores, como la STS de 10 de febrero de 1997. En esta Sentencia el Tribunal excluye la posibilidad de que la sanción impuesta al titular de una licencia de autotaxi encuentre la cobertura legal precisa en el artículo 21 LrBRL por cuanto dicha norma de presunta habilitación no contiene la definición de ningún tipo de infracción, quedando excluida por tanto del cumplimiento de la función encomendada al principio de legalidad por el artículo 25.1 CE.

No obstante lo anterior, y aunque ya ha quedado apuntado en otro lugar, sirva de recordatorio que la STS de 2 de abril de 1991 estimó, precisamente, que la legislación básica local ofrecía habilitación legal suficiente para la sanción impuesta a un taxista regulada en una Ordenanza Local ${ }^{31}$. Y éste parece ser el criterio que sigue Garrido Falla en el Voto Particular, cuando, para justificar la legalidad de la sanción impuesta, basa su argumentación en la titularidad municipal del transporte público de viajeros y en las facultades de organización y reglamentación del mismo por parte de las Entidades Locales.

El segundo bloque normativo al que presta atención el TC es el configurado por la legislación sectorial (FJ 8. ${ }^{\circ}$ ), acudiendo a tres instrumentos normativos, dos estatales y uno autonómico, de los cuales dos de ellos

${ }^{31}$ En este mismo sentido la STS de 16 de julio de 1998 considera que las infracciones y sanciones en materia de la ORA reguladas en la correspondiente Ordenanza Municipal del Ayuntamiento de Madrid encuentran cobertura suficiente en los artículos 4.1 f) y $21.1 \mathrm{k}$ ) LrBRL y en el 59 TRRL. 
apenas plantean dudas sobre su eficacia en la materia que nos ocupa. En efecto, la alusión al Reglamento Nacional de los Servicios Urbanos e Interurbanos de 1979, cuyo régimen sancionador reproduce en sus líneas generales la Ordenanza Municipal, es rechazada al tratarse de una norma reglamentaria postconstitucional que regula infracciones y sanciones cuando ya regía la reserva de ley ex artículo $25.1 \mathrm{CE}{ }^{32}$. Por su parte, la remisión a la normativa autonómica, Ley de Ordenación y Coordinación de los Transportes Terrestres de 27 de noviembre de 1998, de la Comunidad de Madrid, en cuyo artículo 16.1.2) se contempla expresamente la suspensión temporal de licencias, tampoco resulta de aplicación por cuanto no había entrado en vigor en el momento de cometerse la infracción sancionada ${ }^{33}$.

Un problema singular se plantea en relación con la tercera norma sectorial a la que acude el Alto Tribunal, toda vez que se trata de la Ley de Ordenación de los Transportes Terrestres, de 30 de julio de 1987, cuyo capítulo séptimo del título tercero, artículos 113 a 118, en el que se regulaban los transportes terrestres incluyéndose el servicio de transporte urbano de autotaxi, fue declarado inconstitucional por falta de competencia estatal por la STC 118/1996. No obstante, la declaración de inconstitucionalidad no alcanzó a los artículos 138 a 142 de la mencionada Ley, donde se contempla un régimen sancionador común a todos los servicios de transporte, de tal manera que, en lo que no se oponga a la normativa autonómica de desarrollo sí será de aplicación tal norma. En este sentido, el artículo 143.3 contempla la sanción de suspensión temporal de licencias para determinadas infracciones tipificadas como muy graves ${ }^{34}$. De modo que, razona el TC, si la norma estatal establece una enumeración

\footnotetext{
${ }^{32}$ La STS de 13 de noviembre de 1995 ya se había ocupado de determinar si existía alguna norma legal que ofreciese cobertura al citado Reglamento de Transportes Urbanos de 1979. En este sentido, el TS acude a la Ley de Ordenación de los Transportes Terrestres de 1987, cuya Disposición Adicional Novena autorizaba al Gobierno para dictar las disposiciones necesarias en desarrollo de la misma. En el ejercicio de tal previsión se aprobó el Real Decreto 1211/1990, de 28 de septiembre, cuya Disposición Derogatoria mantiene la vigencia del reglamento de 1979. De lo expuesto, el TS deduce que, «sí una correcta interpretación del artículo 25.1 de la Constitución permite que la propia Ley haga suyo un régimen de infracciones y sanciones, no es en cambio admisible que una autorización al Gobierno para dictar Reglamentos en ejecución y desarrollo de la Ley haga posible que otorgue cobertura a un régimen sancionador (infracciones, sanciones y procedimiento) distinto del de la Ley que desarrolla» (FD $\left.4 .^{\circ}\right)$.

33 En este sentido, la STC 45/1994 viene a señalar que las leyes sólo pueden dar cobertura suficiente a las normas reglamentarias anteriores cuando se trata de hechos pro futuro, y nunca antes de que su comisión se haya producido con anterioridad a la entrada en vigor de aquélla.

${ }^{34}$ V. gr. la prestación de servicios de transporte sin título administrativo, la prestación de tales servicios en condiciones que puedan llegar a afectar la seguridad de los usuarios, o la reiteración de infracciones muy graves.
} 
tasada de supuestos de infracción muy grave que llevan aparejada la sanción de suspensión temporal, tampoco la citada Ley puede dar cobertura suficiente a la Ordenanza debatida, por cuanto ésta «prevé para todas las infracciones graves (por tanto no sólo para tipos singulares de infracciones muy graves) la sanción de suspensión de licencia» (FJ 8. $\left.{ }^{\circ}\right)$.

En conclusión, la sanción impuesta vulnera el derecho fundamental a la legalidad sancionadora del demandante de amparo, puesto que la reiterada norma sectorial estatal sólo otorgaría cobertura a la suspensión de licencias en los casos de comisión de infracciones muy graves ${ }^{35}$.

Esta infructuosa búsqueda de norma legal habilitante de la sanción impuesta provoca una reflexión del Magistrado disidente no exenta de cierta ironía, cuando tras constatar el vacío jurídico operado por la STC 118/1996 y la ausencia de normativa autonómica, que, a su juicio, supondría la desregulación total de la actividad del transporte público de taxis, concluye expresando su consuelo por cuanto «durante esta "vacación legislativa" los posibles infractores no sabían que todo les estaba permitido». No le falta razón al Magistrado Garrido Falla en esta afirmación en la que subyace una atenuada crítica al fallo mayoritario, por cuanto hubiese sido deseable que el TC hubiese entrado a enjuiciar con mayor detenimiento y profusión las posibilidades interpretativas que le ofrece la legislación básica local.

\section{CONCLUSIONES}

En las páginas precedentes hemos intentado exponer la en exceso muy concisa e inadecuada doctrina de la STC 132/2001 dada la enjundia de los problemas que aborda. El TC ha optado por la solución más sencilla al trasladar mecánicamente y sin excesivos esfuerzos al ámbito de las relaciones entre la Ley y la Ordenanza Municipal los principios que rigen entre la Ley y el Reglamento, ya sean estatales o autonómicos, descartando ulteriores valoraciones inductivas sobre la posibilidad de que algún mecanismo jurídico module la rígida reserva de ley formal.

Desde esta perspectiva, la hermenéutica constitucional resulta notablemente desfallecida por insuficiente, pero no deja lugar a dudas sobre

\footnotetext{
${ }^{35}$ Recientemente la STS de 18 de octubre de 2000, Ar. 439, ha venido a señalar que, en el supuesto de que la sanción de suspensión temporal de licencia se imponga por violar el régimen de las tarifas, la normativa aplicable se concretaría en la Ordenanza Local y en el Reglamento Nacional de 1979, por cuanto la Ley de Ordenación de los Transportes de 1987 y su Reglamento de 1990 dejan a salvo las competencias locales.
} 
los requisitos que han de concurrir para que se ajuste a la legalidad la regulación, por parte de las Ordenanzas Municipales de infracciones y sanciones en las materias de competencia y titularidad local. De tal manera que la existencia de una Ley previa, bien sea estatal o autonómica, que ofrezca suficiente cobertura a las citadas infracciones y sanciones se convierte en el presupuesto básico que determina la legalidad de las mismas.

En este sentido, la Sentencia resulta coherente con la interpretación tradicional del artículo 25.1 CE, si bien hubiese sido deseable que el TC hubiera entrado con mayor decisión a enjuiciar las posibilidades de modulación del principio de reserva de ley sancionadora que ofrecen tanto la naturaleza representativa del Pleno de las Corporaciones Locales, como la existencia de un interés local en la materia de que se trate, máxime si tenemos en cuenta que la jurisprudencia del propio TC y del TS no ha mantenido una línea interpretativa uniforme. En definitiva, el fallo constitucional viene a poner punto, mucho nos tememos que simplemente, y seguido a un interesante problema del Derecho municipal español, obligando así al legislador sectorial a establecer un acabado régimen de infracciones y sanciones en las materias que desarrolla con el objeto de dotar de cobertura legal suficiente a las Ordenanzas Locales. 